\title{
Warning: Don't Infer Regional Inflation Differences from House Price Changes
}

\section{Charles S. Gascon, Regional Economist}

Andrew Spewak, Senior Research Associate

$\mathrm{f}$ house prices in one metropolitan statistical area (MSA) are increasing much faster than in another MSA, should one infer that overall inflation is also much faster in the former? No. Consider the nation's two largest MSAs: New York, New York, and Los Angeles, California. In New York, house prices have grown only about 2 percent annually since 2011, according to the Federal Housing Finance Agency house price index (HPI). Meanwhile, house prices have skyrocketed in Los Angeles, growing over 8 percent annually during the same period. If house prices were a proxy for regional inflation, this would imply higher inflation in Los Angeles than in New York. In reality, despite the major differences in house price growth, overall inflation trends have been very similar in these two areas. According to the regional consumer price indexes (CPIs), prices in both areas have increased a little over 1 percent per year during this period.

In this essay, we examine incongruities between regional house price growth and regional inflation and why house price growth doesn't accurately reflect overall changes in the cost of living.

\section{Regional Disparities}

Figure 1 maps average annual HPI growth from 2011 to 2015 across the nation's 381 MSAs. HPI growth is fastest on the West Coast. Conversely, HPI growth throughout the rest of the country has been relatively slow: 200 MSAs have rates between 0 and 2.5 percent. The general intuition is that, since housing is the largest expenditure for most households, variations in house prices should closely follow variations in the overall cost of living. ${ }^{1}$

However, despite large regional differences in house price growth, regional inflation rates vary little across the country. Figure 2 maps inflation in MSAs from 2011 to 2015, as measured using the implicit price deflator from the Bureau of Economic Analysis (BEA). ${ }^{2}$ In all but three

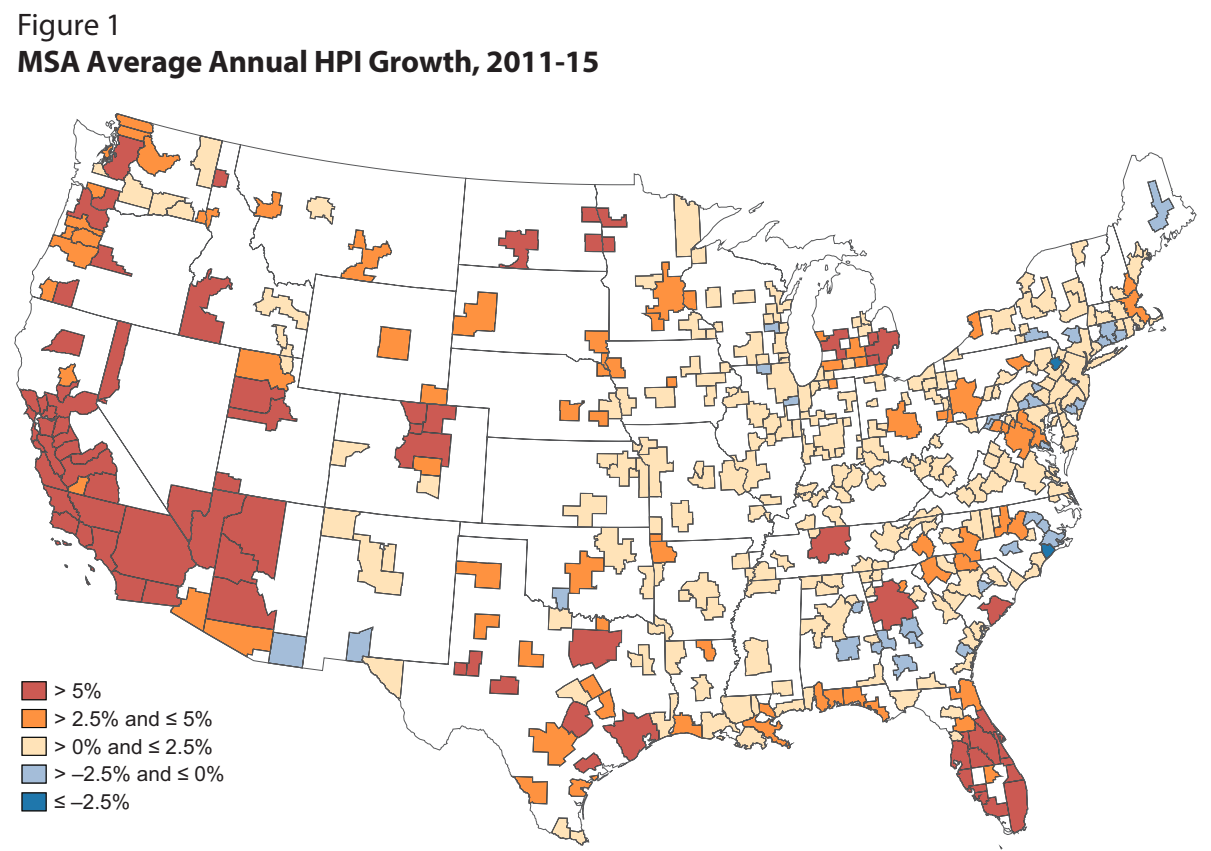

SOURCE: Federal Housing Finance Agency. 
Figure 2

MSA Average Annual Implicit Price Deflator Growth, 2011-15

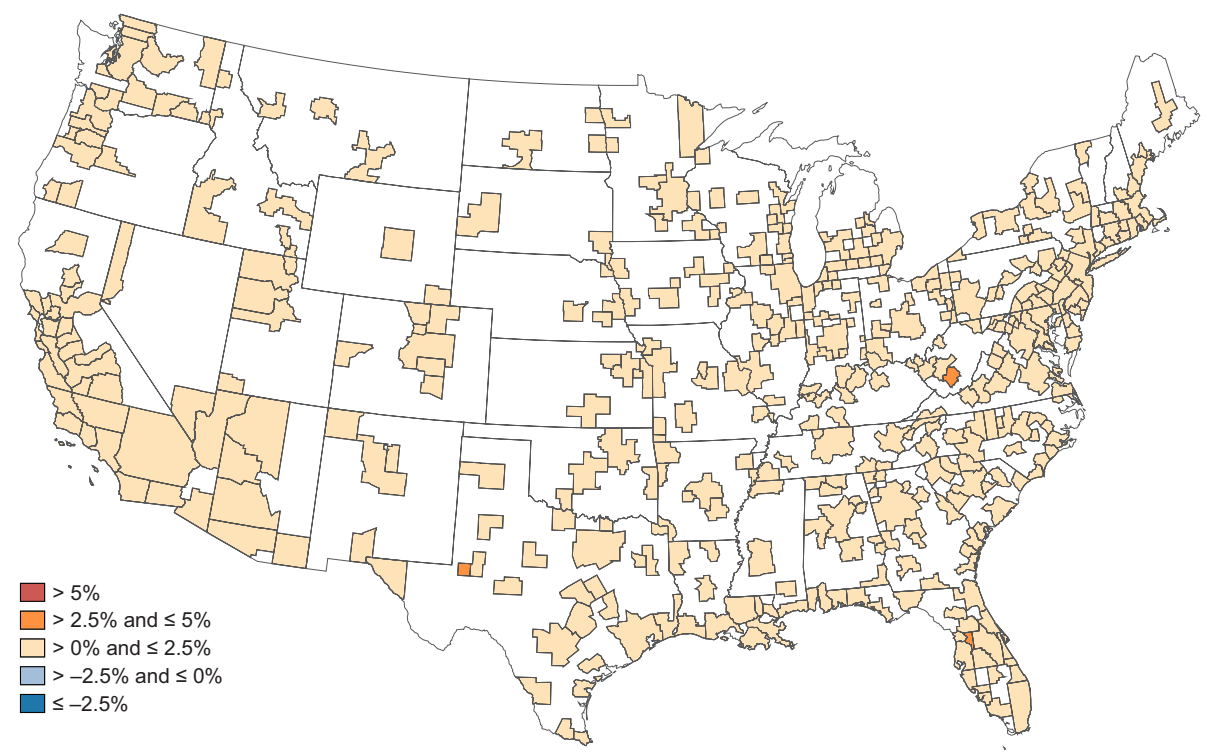

SOURCE: BEA.

MSAs, the annual rate of growth is between 0 and 2.5 percent, close to the national average of 1.3 percent. $^{3}$

\section{House Price Growth versus Changes in the Cost of Living}

There are a few reasons why regional house price growth does not measure regional inflation and thus does not accurately reflect changes in the cost of living. First, house prices capture both the price of housing services (i.e., shelter) and the value of housing as an asset (which is primarily the price of the land). The latter drives most of the change in house prices. As the value of housing increases (decreases), the return on investment for homeowners increases (decreases), driving up (down) the price that consumers will pay for housing. Changes in house prices are useful for studying broad housing market trends, as well as household wealth, but do not necessarily reflect changes in the actual cost of housing services for homeowners.

Second, for most households, their cost of housing is little changed by movements in the price of their house. According to the Census Bureau, 95 percent of homeowners remain in the same house from one year to the next. For a non-mover household, the mortgage payment, by far the largest housing expenditure, generally does not change from one year to the next. Only the mover household, which has to buy or renegotiate its mortgage, will experience a significant difference in housing costs. ${ }^{4}$

Third, the HPI does not properly measure the change in costs for renters, who make up one-third of U.S. households. If increases in house prices were perfectly passed through to rent prices, then house prices would accurately measure housing costs for renters. However, the two rarely move in perfect synchrony.

There exist market-based rent measures from private sources such as Reis and Zillow. However, these are not ideal for estimating rental costs in an analysis such as this one because they are not adjusted for quality. For example, consider a fast-growing MSA in which new apartment buildings are constantly springing up as old buildings are being demolished. In this area, rents, according to marketbased measures, will increase rapidly, as more people move to newer, nicer buildings that charge higher rents. However, rent prices would have changed anyway from one year to the next due to demographic shifts, property laws, and other reasons not related to the quality of housing. Thus, these rents reflect that renters are paying for a different kind of housing — higher quality or newer housing — and do not necessarily measure the actual inflation of rent costs.

\section{House price growth is not an accurate predictor of regional inflation.}

Lastly, even if properly measured, growth in housing costs should still vary more than inflation because of substitution effects. In general, the housing expenditure weight - the share of household income spent on housingis about 20 percent and not sensitive to changes in prices. 


\section{Figure 3}

MSA Average Annual Implicit Rent Deflator Growth, 2011-15

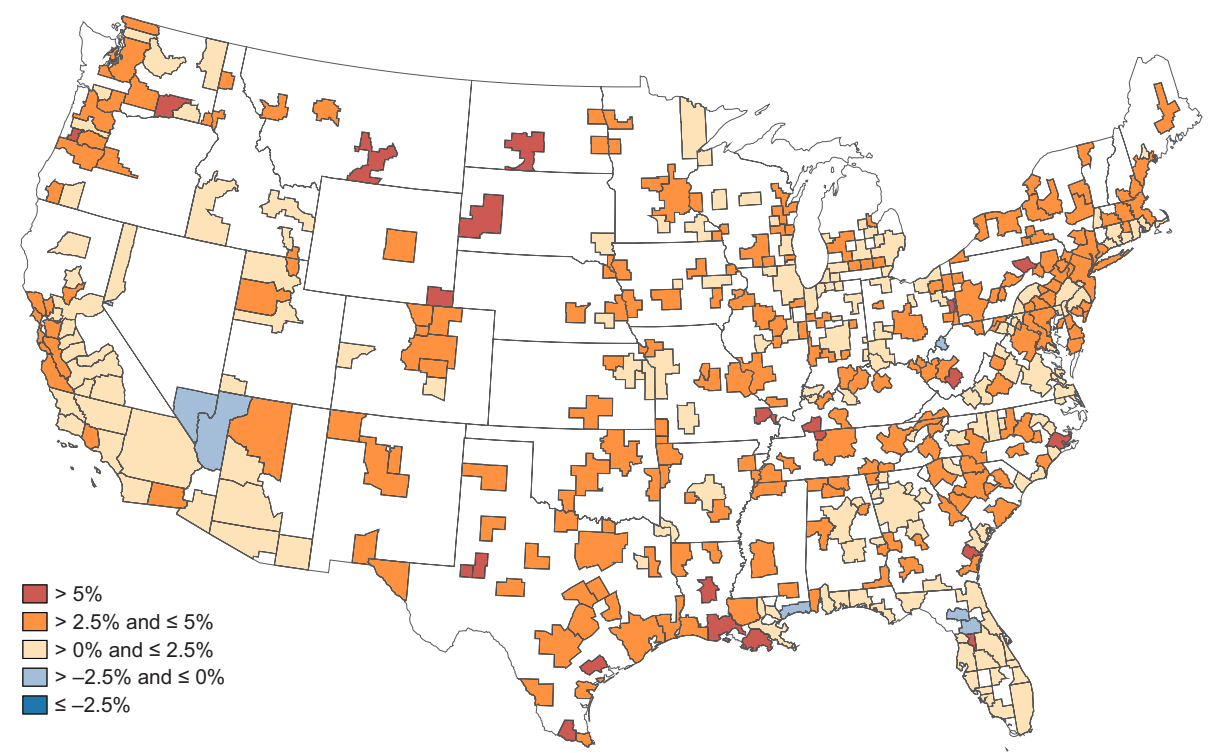

SOURCE: BEA.

\section{Figure 4 \\ MSA Implicit Price Deflator Regressed on MSA Implicit Rent Deflator}

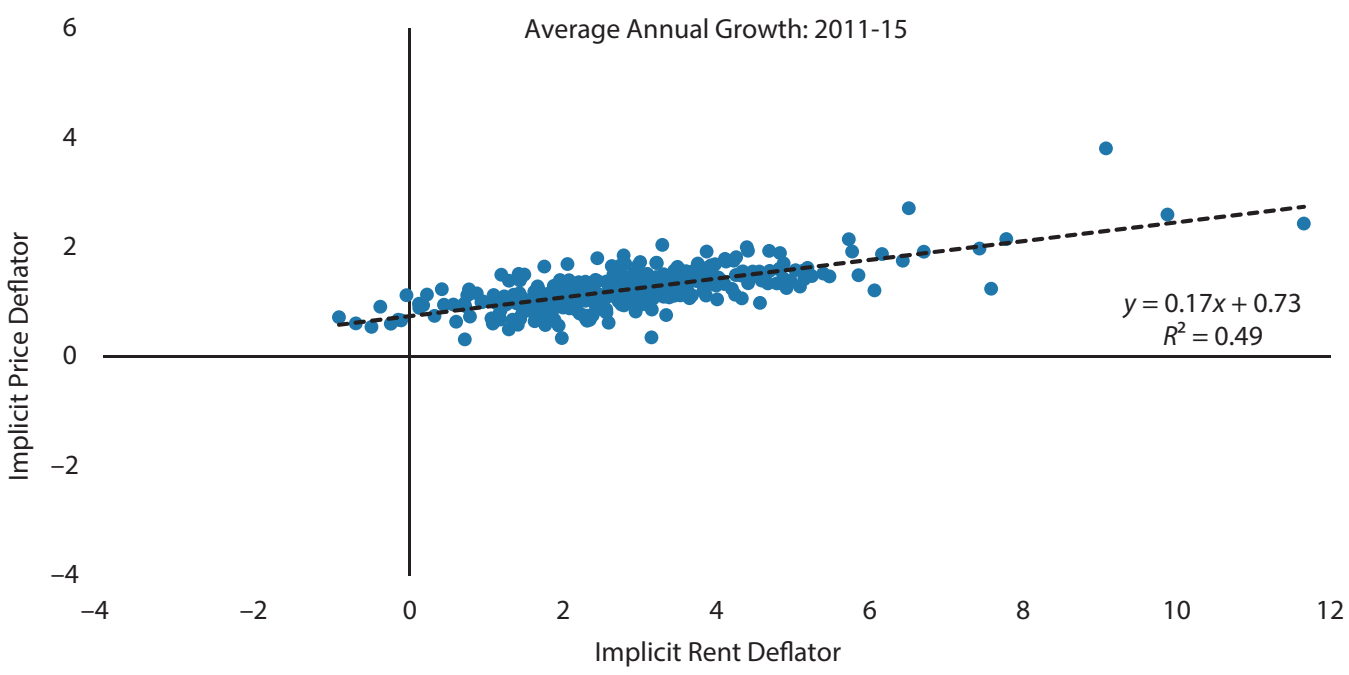

SOURCE: BEA.

As prices rise, households respond by purchasing less or cheaper housing, keeping the housing expenditure weight constant. It works the other way too: If prices decrease, households tend to buy more or costlier housing, again keeping the expenditure weight and inflation steady. As a result, the cost of living stays relatively stable compared with the change in house prices.

\section{Properly Measuring Housing Costs}

Our preferred measure of housing costs is rents from the $\mathrm{BEA}$, which combine rent prices observed directly in the Census Bureau American Community Survey and ownerimputed rents calculated from Bureau of Labor Statistics consumer expenditure data. ${ }^{5}$ To evaluate changes in rents over time, we construct an implicit rent deflator, which is analogous to the overall implicit price deflator. ${ }^{6}$ These rents data measure only the cost of housing-for both owners 
and renters-instead of the value of the housing stock, and they adjust for the quality of housing, so they more accurately reflect what residents actually pay for housing.

As Figure 3 shows, rent growth is more evenly distributed geographically than house price growth. Rents are growing particularly rapidly in some regions, such as the Gulf Coast, but for most of the country, rent growth has been modestly positive. In 351 of the 381 MSAs in the data, house prices grew by between 0 and 5 percent annually from 2011 to 2015.

The (lack of) regional variation in rent growth aligns closely with the variation in inflation rates. Whereas there is little to no correlation between house price growth and inflation, there is a strong correlation between rent growth and inflation. As shown in Figure 4, about half of the variation of growth in the implicit price deflator across MSAs can be explained by growth in the implicit rent deflator, consistent with our expectation that housing costs will drive inflation. ${ }^{7}$

\section{Conclusion}

House price growth has varied significantly nationwide since the end of the Great Recession in 2009: In some MSAs, prices have grown as quickly as 7 percent annually, while others have seen prices decline almost as quickly, with many more MSAs falling somewhere in between. Since households spend more on housing than any other good or service, we would expect that inflation rates would show the same variation. They do not.

To analyze changes in the actual cost of living, one must look at measures more sophisticated than house prices, such as rents data from the BEA, which combine actual rents paid with estimates of owner-equivalent rents. Using these data, we show that changes in the cost of living do vary regionally, but considerably less than house prices. There still exists more variation in rents than in inflation, due in part to the fact that households will adjust how much housing they purchase when the price changes. Overall, though, these rents data accurately capture changes in how much households pay for housing, which explain a significant portion of regional inflation rates.

\section{Notes}

1 See Coughlin, Cletus C.; Gascon, Charles S. and Kliesen, Kevin L. "Living Standards in St. Louis and the Eighth Federal Reserve District: Let's Get Real." Federal Reserve Bank of St. Louis Review, Fourth Quarter 2017, 99(4), pp. 377-94; https://doi.org/10.20955/r.2017.377-394.

2 The regional price parities (RPPs) measure an area's cost of living as a percent of the national average. The implicit price deflator, a measure of regional inflation, is constructed by multiplying an area's RPP by the national rate of personal consumption expenditures (PCE) inflation.

3 The consumer price index (CPI), a more well-known measure of prices, is available for a longer time sample but is available for only 27 MSAs.

4 For all households, property taxes and homeowner insurance costs may go up with the value of the house, but these expenditures are relatively small portions of overall housing costs.

5 Owner-imputed rents are defined by the BEA as the amount of money homeowners would have spent had they been renting their homes. It is a close approximation for how much a homeowner spends on mortgage payments, property taxes, and other housing costs.

6 The BEA publishes rent RPPs, which strip out all non-rent expenditures from the RPPs. However, the BEA does not calculate an implicit rent deflator as it does for overall prices. We construct this implicit rent deflator ourselves by multiplying an area's rent RPP by the weighted average of national rent PCE and national owner-imputed rent PCE, assuming one-third of households are renters. We have tested the robustness of our results by constructing this deflator using only rent PCE and only owner-imputed rent PCE.

\footnotetext{
7 This result is consistent with the findings of Rappaport and Redmond (2016), who use CPI data to measure the relationship between rents and inflation in western MSAs. See Rappaport, Jordan and Redmond, Michael. "Consumer Price Inflation and Rising Rents in the West." Federal Reserve Bank of Kansas City Main Street Views, December 19, 2016; https://www.kansascityfed.org/publications/research/mb/articles/2016/consumer-price-inflations-rising-rent-west.
} 